\title{
Resilience of the Territory to the Occurrence of Natural Hazards
}

\author{
Alena OULEHLOVÁ ${ }^{1}$
}

\begin{abstract}
The article deals with the issue of increasing resilience of the territory by reducing its vulnerability to natural hazards. The present state of the issue is focused on the analysis of the United Nations' involvement in disaster response where organising World Conferences on Disaster Risk Reduction is viewed as a key moment. Subsequently, tools used for assessing the vulnerability and resilience to disasters are examined. Based on the results of the current state of knowledge and deficiencies in the concerned area, a process has been proposed to evaluate the vulnerability and risk of the territory to the occurrence of natural hazards with the aim of ensuring acceptable area safety. Applicability of the proposed process of the vulnerability and risk assessment of the territory to natural hazards is presented on an example of a municipality. Verification on the selected municipality has proven the merit of the proposed procedure.
\end{abstract}

Keywords: disaster, municipality, resilience, risk, vulnerability assessment

\section{Introduction}

The increasing occurrence of natural hazards has a wide range of negative impacts on the population, property, environment, economy or social system. The economic impacts and human losses caused by natural hazards are differentiated depending on the level of development of the world. Global interconnectivity raises shared responsibility and the need to prevent, solve and eliminate the consequences of hazards, hence the need for crisis management is growing.

For this reason, countries and international organisations have started to employ a holistic and multidisciplinary approach to the safety, risk management and crisis management. Ensuring environmental and human safety is one of the biggest challenges today. The main responsibility for the disaster risk management should be taken by the central government. Governments must decide what degree of risk they are willing to accept and what tools they will use for implementing risk control. [1] For this purpose, the public and the private sector create crisis management authorities at central and local levels and by means of legal regulations they set requirements for prevention, minimisation and monitoring of risks as well as preparedness and response. Next, they adopt technical, organisational, financial and information measures which ensure the resistance of the society to disasters. All these activities are supposed to contribute to the minimisation of negative impacts while strengthening the country's sustainable development.

Head of the Crisis Management Group, University of Defence, Faculty of Military Leadership; e-mail: alena. oulehlova@unob.cz; ORCID: 0000-0003-1685-5137 


\section{The Theoretical Part}

In the context of historical development, a shift from a reactive to preventive approach to dealing with disasters is observed. The basic element for effective implementation of preventive measures and crisis planning is the vulnerability assessment of the territory which can be endangered by individual threats. The current situation suggests that it is essential to address the issues of increasing resilience, mitigation and adaptation of the area to the occurrence of natural hazards as necessary conditions for improving the area safety and ensuring sustainable development.

\section{World Conferences on Disaster Risk Reduction}

In the United Nations (UN), the beginnings of international coordinated aid in the aftermath of natural disasters date back to the 1960s. This was mainly about providing financial and material relief to affected countries. The first breakthrough in a coordinated approach was the decision to launch the International Decade for Natural Disaster Reduction [2] effective from 1990 to 1999. The main focus was on resource planning, preparedness and prevention of natural disasters, public education, creation of disaster scenarios, establishment or strengthening the early warning systems, land use planning to reduce vulnerability, mapping the areas with frequent occurrence of disasters, increasing the number of experts and their resources.

In 1994, the World Conference on Disaster Risk Reduction was held in Yokohama, Japan. At this conference, ten principles [3] were established representing a global integrated approach to disaster risk reduction.

The World Conference on Disaster Risk Reduction in Kobe, Japan was held a month after the devastating earthquake and the subsequent tsunami in the Indian Ocean which occurred in December 2004 and claimed 230,000 human lives. Lasting deficiencies and problems were identified. They were related to management areas; identification, assessment, risk monitoring and early warning; knowledge management and education; reduction of risk factors, preparedness for effective response and recovery. [4]

The third World Conference on Disaster Risk Reduction adopted the Sendai Framework for Disaster Risk Reduction 2015-2030. [5] This framework defines four priorities for action-understanding the risk, strengthening the disaster risk governance to manage the disaster risk, investing in disaster risk reduction for resilience, enhancing disaster preparedness for effective response, and to "Build Back Better" [5] in recovery, rehabilitation and reconstruction. These priority actions became the basis for their implementation in each of the priority areas of management (local, national, regional, global level). To reduce the damage caused by disasters, the Sendai framework [5] sets seven global targets which are supposed to contribute to the achievement of the new sustainable development goals.

The results of all the world conferences point to the necessity of implementing a comprehensive integrated hazard risk assessment as a necessary basic element for successful hazard prevention, as well as an effective tool for crisis planning. 


\section{Vulnerability and Resilience Assessment}

Vulnerability is a deficiency, weakness or state of the analysed asset which can be exploited by the threat to exert its undesirable influence. Vulnerability is the asset's property and it expresses how sensitive the asset is to a given threat. Vulnerability results from an interaction between the threat and the asset. The level of vulnerability is assessed by sensitivity and criticality factors. [6] In the international concept of hazard risk reduction, vulnerability is associated with poverty, the socially disadvantaged groups, poor state of health and depletion of resources. The following factors are considered to be the powerhouse of disaster vulnerability: [7] [8] [9]

- economic factors;

- social factors;

- political factors;

- environmental factors;

- geographical factors.

Vulnerability is not static, but changes over time similarly to the population and physical changes of the environment. Currently, there is little agreement how it should be measured. [7] Vulnerability is difficult to measure objectively. Although there are activities to reduce vulnerability and increase resilience, they are very specific and relate to a certain type of danger and a population group.

Vulnerability is evaluated differentially in various areas of human activities. Examples of vulnerability measurements can be the Disaster Risk Index (DRI) [10] or the Social Vulnerability Index (SoVI). [11]

Resilience expresses the ability of a system or society to resist, mitigate, accept and recover from the impacts of disruptive events in a timely and effective manner, including preservation and restoration of its essential structure and functions. [12] According to Moench, [13] concepts of resilience take two forms - hard and soft. Hard resilience is the direct strength of structures or institutions which are under a threat. Soft resilience is the ability of systems to absorb and recover from the impact of disruptive events without fundamental changes in function or structure.

\section{Methods}

Various methods were used to develop a vulnerability and risk assessment proposal. In default of suitable indicators, the brainstorming method [14] [15] with selected experts was used. The Delphi method was used to gain the opinion of experts on the significance of factors and proposed vulnerability indicators. The Pearson correlation coefficient and the Spearman correlation coefficient [16] were used to investigate dependencies between individual factors of vulnerability. For each indicator of the vulnerability factors, the Wilcoxon pair test [16] was used to compare pairs of individual indicators of the vulnerability factors and to identify differences between the indicators. The purpose of the local investigation was to verify the functionality of the proposed methodological process of the vulnerability assessment and a proposal of measures to mitigate the hazard impacts. 


\section{Proposal for Vulnerability and Risk Assessment of the Territory}

Based on the current situation, it was found that a comprehensive vulnerability assessment is a time and data consuming issue. In accordance with the UN approaches, physical, social, economic and environmental factors were chosen as the main factors influencing the extent of vulnerability.

For these factors, indicators were suggested and characterised. It is a new innovative approach to the vulnerability assessment in the Czech Republic. At the same time, it is the first proposal of a comprehensive risk assessment of natural hazards for the needs of increasing the resilience of the territory. The indicators were chosen in order to gain a complete picture about the assessed territory and the possibility of re-evaluation. The indicators represent a set of information which characterises the territory and potential impacts of a hazard. Coefficients are assigned to the indicators. Each indicator has values in the interval of 1-5 and is complemented by a verbal characteristic of each level of the interval. The numerical and verbal characteristics of individual indicators were set on the basis of information from public databases as well as the qualified assessment after a discussion with experts.

In the first step, the characterisation of the territory was done with respect to the implementation of the risk assessment. In the second step, the risk analysis was as follows:

the frequency of natural hazards occurring per one year assuming values 1-5;

vulnerability of the territory based on individual factors and vulnerability indicators. Overall vulnerability is derived from the sum of the physical, environmental, social and economic vulnerability factors. The vulnerability calculation is performed as a sum of these factors, where each factor is multiplied by the weight allocated to it based on the Delphi method results.

$$
V_{\mathrm{z}, \mathrm{j}}(\tau)=\left(v_{\mathrm{fyz}} \times V_{\mathrm{fyz}, \mathrm{j}}(\tau)\right)+\left(v_{\mathrm{env}} \times V_{\mathrm{env}, \mathrm{j}}(\tau)\right)+\left(v_{\mathrm{soc}} \times V_{\mathrm{soc}, \mathrm{j}}(\tau)\right)+\left(v_{\mathrm{eko}} \times V_{\mathrm{eko}, \mathrm{j}}(\tau)\right)
$$

where:

$V_{z, j}$ - overall vulnerability of the territory for the $j$-th source of danger in time;

$v_{\text {fyz }}$ - weight of the physical vulnerability of the territory;

$V_{\mathrm{fyz}, \mathrm{j}}(\tau)$ - factor of the physical vulnerability of the territory for the $j$-th source of danger in time;

$v_{\text {env }}$ - weight of the environmental vulnerability of the territory;

$V_{\text {env,j }}(\tau)$ - factor of the environmental vulnerability of the territory for the $j$-th source of danger in time;

$v_{\mathrm{soc}}$ - weight of the social vulnerability of the territory;

$V_{\text {soc,j }}(\tau)$ - factor of the social vulnerability of the territory for the $j$-th source of danger in time; $v_{e k o}$ - weight of the economic vulnerability of the territory;

$V_{\text {eko,j }}(\tau)$ - factor of the economic vulnerability of the territory for the $j$-th source of danger in time;

$(\tau)$ - time.

For the physical vulnerability factor, these indicators were set:

- vulnerability of the road network $\left(V_{\text {sil }}\right)$;

- vulnerability of the railway network $\left(V_{\bar{z} e l}\right)$; 
- vulnerability of the energy infrastructure $\left(V_{\text {ene }}\right)$;

- vulnerability of the water management infrastructure $\left(V_{\text {vod }}\right)$;

- vulnerability of the information and communication infrastructure $\left(V_{\text {iko }}\right)$;

- size of the affected territory $\left(V_{\text {zas }}\right)$;

- character of the built-up area $\left(V_{\text {zst }}\right)$;

- sufficiency of the Integrated Rescue System forces and resources, as well as coordination in dealing with an emergency situation ( $\left.V_{\text {nas }}\right)$;

- recovery of the territory by ensuring the basic functions of the territory $\left(V_{\text {obn }}\right)$.

To assess the factor of the environmental vulnerability of the territory, these indicators were proposed:

- vegetation cover $\left(V_{\mathrm{vkr}}\right)$;

- slope of the terrain $\left(V_{\mathrm{skl}}\right)$;

- $\quad$ specially protected areas $\left(V_{\text {zchú}}\right)$;

- water erosion $\left(V_{\text {ver }}\right)$;

- slope instability $\left(V_{\mathrm{svn}}\right)$;

- saturation $\left(V_{\text {nsy }}\right)$;

- rate of stream flow $\left(V_{\mathrm{vot}}\right)$;

- water level in boreholes and capacity of springs ( $\left.V_{\text {hld }}\right)$.

To assess the factor of the social vulnerability of the territory, these indicators were proposed:

- number of people at risk $\left(V_{\text {pos }}\right)$;

- population density $\left(V_{\mathrm{hob}}\right)$;

- number of injured people and victims of an emergency or crisis situation $\left(V_{\mathrm{pob}}\right)$;

- prediction of occurrence of natural hazards $\left(V_{\mathrm{pv}}\right)$.

To assess the factor of the economic vulnerability of the territory, these indicators were proposed:

- unemployment rate $\left(V_{\text {nez }}\right)$;

- damage caused by natural hazards $\left(V_{\text {ško }}\right)$.

In the third step, a risk assessment is carried out. On the basis of the discovered frequency and vulnerability, the risk for the $j$-th hazard source is calculated. The risk level $R$ for the $j$-th hazard source is the product of the index value of probability $P_{\mathrm{j}}$ of activation of the $j$-th hazard source and the value of the overall vulnerability of the territory for the $j$-th hazard source $V_{z, j}$ in time $(\tau)$ expressed by this formula (2):

$$
R_{\mathrm{j}}(\tau)=P_{\mathrm{j}}(\tau) \times V_{\mathrm{z}, \mathrm{j}}(\tau)
$$

where:

$R_{\mathrm{j}}(\tau)$ - risk level for the $j$-th hazard source;

$P_{\mathrm{j}}(\tau)$ - frequency of action of the $j$-th hazard source;

$V_{z, j}(\tau)$ - overall vulnerability of the territory for the $j$-th hazard source in time;

$(\tau)$ - time. 
The calculated risk level $R_{\mathrm{j}}(\tau)$ is in the interval $\langle 0 ; 25\rangle$. Individual values of the risk level were characterised and they are indicated in Table 1. The division of the risk level and its characterisation was performed on the basis of brainstorming.

Table 1. Characterisation of the risk level $R_{j}(\tau)$ in relation to the risk of the $j$-th hazard.

[Edited by the author.]

\begin{tabular}{|l|l|}
\hline Risk level $\boldsymbol{R}_{\mathbf{~}}(\boldsymbol{\tau})$ & Characterisation of the risk \\
\hline$(0 ; 3.5\rangle$ & Insignificant risk. There is no need to introduce countermeasures. The risk is monitored. \\
\hline$(3.5 ; 10\rangle$ & $\begin{array}{l}\text { Acceptable risk. There is no need to introduce countermeasures. The countermeasures are } \\
\text { introduced in case of low costs compared with the benefits. The risk must be monitored. }\end{array}$ \\
\hline$(10 ; 19\rangle$ & $\begin{array}{l}\text { Unwanted risk. It is necessary to introduce countermeasures in order to reduce the risk } \\
\text { to an acceptable level. The reduction costs should be proportional to the value of the } \\
\text { protected assets. To evaluate the effectiveness of the proposed countermeasures, single- } \\
\text { criterion and multi-criteria project evaluation methods are applied. }\end{array}$ \\
\hline$(19 ; 25\rangle$ & $\begin{array}{l}\text { Unacceptable risk. It is necessary to introduce countermeasures immediately in order to } \\
\text { reduce the risk to an acceptable level. }\end{array}$ \\
\hline
\end{tabular}

Based on the findings, it is necessary to decide on the scope and method of the implementation of preventive, mitigation and adaptation measures, sources of funding for the proposed countermeasures as well as the risk monitoring process.

The procedure allows to reassess the findings at regular intervals and perform their evaluation, which facilitates the interpretation, simplicity and complexity of the output. In the long-term and repeated assessment of the risk and vulnerability of the territory, they can be used for evaluation of the success of implemented measures in the territory, monitoring trends in achieving resilience and sustainable development of the territory.

\section{Validation of the Vulnerability and Risk Assessment Proposal}

In order to verify the suitability and applicability of the vulnerability and risk assessment procedure by selected natural hazards, municipalities of different types were approached according to their administrative structure.

In the first step, the territory of the municipality was characterised regarding general data and natural conditions as well as management of crisis situations and experience with crisis management in the territory. Subsequently, the frequency of the occurrence was determined for selected hazards and the vulnerability assessment of the territory was carried out using proposed indicators. Finally, the risk was calculated.

In the municipality, the risk assessment was performed for all the dangers for which an alert is issued through the Integrated Warning Service System of the Czech Hydrometeorological Institute. Characterisation of individual hazards and their frequency is seen in Table 2. 
Table 2. Hazard characterisation.

[Edited by the author.]

\begin{tabular}{|l|l|l|l|l|}
\hline Phenomenon & Danger & Characterisation & $\begin{array}{l}\text { Value } \\
\boldsymbol{P}_{\mathbf{j}}(\boldsymbol{\tau})\end{array}$ & Impact \\
\hline Flooding & Extreme flood threat & Flood level 3, $\mathrm{Q}_{100}$ & 3 & moderate \\
\hline Snow & Extreme snow cover & New snow $>30 \mathrm{~cm} / 24 \mathrm{hrs}$ & 3 & moderate \\
\hline \multirow{2}{*}{ Temperature } & Extremely high temperatures & $\mathrm{T}_{\max }>37^{\circ} \mathrm{C}$ & 2 & low \\
\cline { 2 - 6 } & Extreme frost & $\mathrm{T}_{\min }<-24^{\circ} \mathrm{C}$ & 3 & moderate \\
\hline Rain & Heavy rainfall & precipitation $>60 \mathrm{~mm} \cdot 24 \mathrm{hrs}^{-1}$ & 5 & very high \\
\hline Wind & Extremely strong wind & gusts $>40 \mathrm{~m} \cdot \mathrm{s}^{1}\left(140 \mathrm{~km} \cdot \mathrm{h}^{-1}\right)$ & 4 & high \\
\hline Freezing rain & Very thick glaze ice & $\begin{array}{l}\text { precipitation }>7 \mathrm{~mm} \text { of freezing } \\
\text { rain }\end{array}$ & 4 & high \\
\hline Storm & Extremely strong thunderstorm & $\begin{array}{l}\text { precipitation } \geq 30 \mathrm{~mm} \text { and gusts }> \\
30 \text { m.s } \mathrm{s}^{-1}\left(110 \mathrm{~km} \cdot \mathrm{h}^{-1}\right)\end{array}$ & 3 & moderate \\
\hline Fire & High fire hazard & $\begin{array}{l}\text { fire hazard index }=5 \text {, forecast } \\
\text { period } \geq 3 \text { days, occurrence in } \\
\text { forest vegetation }\end{array}$ & 2 & low \\
\hline
\end{tabular}

The vulnerability assessment of the territory was performed for individual hazards. Each indicator in individual vulnerability factors was assigned a value of $1-5$ which was multiplied by the weight of the indicator. The assigned values of indicators as well as the overall results of the vulnerability assessment of the municipality are presented in Table 3.

Table 3. The vulnerability assessment of the municipal territory.

[Edited by the author.]

\begin{tabular}{|c|c|c|c|c|c|c|c|c|c|}
\hline & 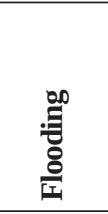 & के & 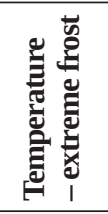 & 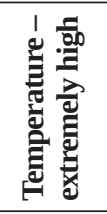 & 誌 & $\overrightarrow{3}$ & 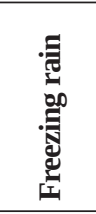 & 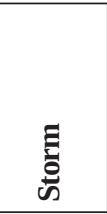 & 韋 \\
\hline$V_{\text {sil,j }}$ & 4 & 4 & 1 & 1 & 3 & 4 & 3 & 2 & 3 \\
\hline$V_{\overline{z e l}, j}$ & 1 & 1 & 3 & 3 & 0 & 2 & 2 & 2 & 4 \\
\hline$V_{\text {ene,j }}$ & 2 & 3 & 4 & 4 & 1 & 3 & 3 & 3 & 3 \\
\hline$V_{\text {vod,j }}$ & 2 & 0 & 3 & 2 & 1 & 0 & 0 & 1 & 0 \\
\hline$V_{\mathrm{iko}, \mathrm{j}}$ & 1 & 1 & 2 & 1 & 0 & 1 & 2 & 1 & 0 \\
\hline$V_{\text {zas,j }}$ & 3 & 3 & 3 & 3 & 3 & 3 & 3 & 3 & 3 \\
\hline$V_{z s t, j}$ & 2 & 2 & 2 & 2 & 2 & 2 & 2 & 2 & 1 \\
\hline$V_{\text {nas,j }}$ & 4 & 2 & 2 & 2 & 1 & 3 & 2 & 1 & 3 \\
\hline$V_{\text {obn, }}$ & 3 & 2 & 3 & 3 & 1 & 2 & 2 & 1 & 1 \\
\hline$\left(v_{\mathrm{fyz}} \times V_{\mathrm{fyz}, \mathrm{j}}(\tau)\right)$ & 2.3895 & 1.9589 & 2.6905 & 2.4005 & 1.244 & 2.13 & 2.0719 & 1.7913 & 1.854 \\
\hline$V_{\mathrm{vkr}}$ & 2 & 2 & 2 & 2 & 2 & 2 & 2 & 2 & 2 \\
\hline$V_{\text {skl }}$ & 1 & 1 & 1 & 1 & 1 & 1 & 1 & 1 & 1 \\
\hline$V_{\text {zchú }}$ & 2 & 2 & 2 & 2 & 2 & 2 & 2 & 2 & 2 \\
\hline$V_{\text {ver }}$ & 2 & 2 & 2 & 2 & 2 & 2 & 2 & 2 & 2 \\
\hline$V_{\mathrm{svn}}$ & 2 & 2 & 2 & 2 & 2 & 2 & 2 & 2 & 2 \\
\hline$V_{\text {nsy }}$ & 2 & 2 & 2 & 2 & 2 & 2 & 0 & 2 & 2 \\
\hline
\end{tabular}




\begin{tabular}{|c|c|c|c|c|c|c|c|c|c|}
\hline & 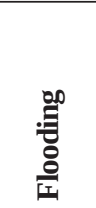 & 孞 & 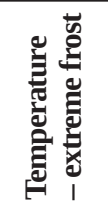 & 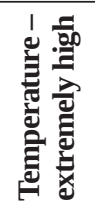 & 吾 & 妾 & 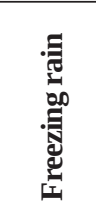 & $\begin{array}{l}E \\
\text { के }\end{array}$ & 部 \\
\hline$V_{\text {vot }}$ & 2 & 2 & 2 & 2 & 2 & 0 & 0 & 2 & 2 \\
\hline$V_{\text {hld }}$ & 5 & 4 & 4 & 5 & 5 & 0 & 0 & 5 & 5 \\
\hline$\left(v_{\mathrm{env}} \times V_{\mathrm{env}}(\tau)\right)$ & 2.2656 & 2.1393 & 2.1393 & 2.2656 & 2.2656 & 1.2643 & 1.0531 & 2.2656 & 2.2656 \\
\hline$V_{\text {poo,j }}$ & 3 & 2 & 2 & 2 & 1 & 2 & 3 & 2 & 1 \\
\hline$V_{\text {hob }}$ & 2 & 2 & 2 & 2 & 2 & 2 & 2 & 2 & 1 \\
\hline$V_{\mathrm{pob}, \mathrm{j}}$ & 1 & 1 & 2 & 2 & 0 & 2 & 1 & 2 & 0 \\
\hline$V_{\mathrm{pv}, \mathrm{j}}$ & 2 & 2 & 2 & 2 & 2 & 2 & 3 & 2 & 1 \\
\hline$\left(V_{\mathrm{soc}} \times V_{\mathrm{soc}, \mathrm{j}}(\tau)\right)$ & 2.0613 & 1.7469 & 2 & 2 & 1.1793 & 2 & 2.2481 & 2 & 0.7469 \\
\hline$V_{\text {nez }}$ & 1 & 1 & 1 & 1 & 1 & 1 & 1 & 1 & 1 \\
\hline$V_{\text {sko,j }}$ & 4 & 1 & 1 & 1 & 3 & 2 & 1 & 1 & 1 \\
\hline$\left(V_{\text {eko }} \times V_{\text {eko,j }}(\tau)\right)$ & 2.8375 & 1 & 1 & 1 & 2.225 & 1.6125 & 1 & 1 & 1 \\
\hline$V_{\mathrm{z}, \mathrm{j}}(\tau)$ & 2.3542 & 1.7482 & 1.9972 & 1.9609 & 1.6984 & 1.7563 & 1.6317 & 1.8144 & 1.4683 \\
\hline
\end{tabular}

In the municipality, the highest coefficients were assigned to the road network and energy infrastructure indicators for all hazards. The highest factor of the physical vulnerability was calculated for the hazard of extreme frost, extremely high temperatures and extreme flood threat. When assessing the factor of the environmental vulnerability of the territory, the highest coefficients were obtained by the indicator of water level in boreholes and capacity of springs which reflects the deepening hydrological drought. Extreme flood hazard, extremely high temperatures, heavy rainfall, extremely strong storms and high fire hazard have the same level of the factor of the environmental vulnerability. The highest factor of the social vulnerability of the territory was calculated for the very thick ice glaze, extreme flood threat and extreme snow cover. Extreme flood threat, heavy rainfall and extremely strong wind received the highest coefficient of damage caused by natural hazards. The placings remained unaltered for the factor of the economical vulnerability of the territory. The highest value of the vulnerability was found in extreme flood threat, extreme frost, extremely high temperatures and extremely strong storms. The lowest value of vulnerability was determined for the high fire hazard.

In the third step, the risk was calculated according to the proposed formula (2). The risks of disasters following the resilience of the assessed territory of the municipality 1 are presented in Table 4.

Table 4. Risk assessment of the territory in the municipality.

[Edited by the author.]

\begin{tabular}{|l|c|l|}
\hline Hazard & $\boldsymbol{R}_{\mathbf{j}}(\boldsymbol{\tau})$ & Risk characteristics \\
\hline Flooding - extreme flood threat & 7.06 & Acceptable risk \\
\hline Snow - extreme snow cover & 5.24 & Acceptable risk \\
\hline Temperatures - extreme frost & 3.99 & Acceptable risk \\
\hline Temperatures - extremely high & 5.88 & Acceptable risk \\
\hline
\end{tabular}


A. OULEHLOVÁ: Resilience of the Territory to the Occurrence of Natural Hazards

\begin{tabular}{|l|c|l|}
\hline Hazard & $\boldsymbol{R}_{\mathbf{j}}(\boldsymbol{\tau})$ & Risk characteristics \\
\hline Rain - heavy rainfall & 8.49 & Acceptable risk \\
\hline Wind - extremely strong wind & 7.02 & Acceptable risk \\
\hline Freezing rain - very thick glaze ice & 6.52 & Acceptable risk \\
\hline Storm - extremely strong storm & 5.44 & Acceptable risk \\
\hline Fire - high fire hazard & 2.94 & Insignificant risk \\
\hline
\end{tabular}

In the municipality, no danger was assessed as unwanted or unacceptable. The hazards of heavy rainfall, extreme flood threat and extremely strong wind are among the considerable risks. It is unnecessary for the local authorities to introduce countermeasures. However, it would be appropriate to implement environmental and technical measures to mitigate their impact. In cooperation with watercourse managers, the bottom of the watercourses must be cleaned and it is necessary to remove mud from ponds. Since the geological subsoil causes rapid outflow of water from the countryside, it is suitable to build drainage equipment on paved areas and equipment to reduce the outflow. It is important to complete the warning system in the municipality and provide the inhabitants with information regarding crisis management, population protection and behaviour in case of an emergency or crisis situation because the website of the municipality lacks such information. Besides implementing the alert system, the municipality, as the elementary school authority, must educate children and other groups of the population through local newspapers or web pages. Also, crossborder cooperation must be strengthened in case of flooding. It is necessary to improve the emergency staff facilities and acquire backup power sources.

\section{Conclusion}

Local authorities must implement disaster risk management as a necessary tool to ensure the safety of the territory. Determination of the vulnerability serves not only as a support of risk management and assessment of the ability of the territory to be resistant to natural hazards but it will promote the sustainable development and implementation of local disaster risk reduction strategies in compliance with the Sendai Framework. [5]

Achieving resilience at the local level requires communication with owners and users of individual plots of land in the municipality. The role of stakeholders in achieving resilience must differentiate the local level depending on their status and availability of resources. Achieving resilience is impossible unless all the stakeholders become aware of their responsibility for preventing emergency and crisis situations, preparedness, response and recovery.

The suggested vulnerability and risk assessment process has verified its applicability. It was the first experience with risk assessment for the municipality. The risk assessment also verified the fulfilment of the crisis legislation requirements at the municipal level as well as the actual approach to the crisis management in the municipality. Although there were no unacceptable risks, the municipality can use the results for updating the emergency documentation, improving preparedness, informing the population and creating mitigation and adaptation measures. In case of regular reassessment of individual risks, the proposed process contributes to increasing resilience and reducing the vulnerability of the territory. 
A. OULEHLOVÁ: Resilience of the Territory to the Occurrence of Natural Hazards

\section{References}

[1] UNISDR: Global Assessment Report on Disaster Risk Reduction 2011. PreventionWeb, 2011. www.preventionweb.net/english/hyogo/gar/2011/en/home/download.html (Downloaded:16.08.2015)

[2] United Nations: A/RES/42/169 International Decade for Natural Disaster Reduction. PreventionWeb, 11.12.1987. www.preventionweb.net/files/resolutions/42_169.pdf (Downloaded: 05.08.2015)

[3] United Nations: E/1994/85 International Decade for Natural Disaster Reduction: Yokohama Strategy for a Safer World. PreventionWeb, 21.06.1994. www.preventionweb.net/files/ resolutions/N9425945.pdf (Downloaded: 10.08.2015)

[4] UNISDR: Hyogo Framework for Action 2005-2015: Building the Resilience of Nations and Communities to Disasters. UNISDR, 22.01.2005. www.unisdr.org/2005/wcdr/intergover/ official-doc/L-docs/Hyogo-framework-for-action-english.pdf (Downloaded: 14.08.2015)

[5] United Nations: A/RES/69/283 Sendai Framework for Disaster Risk Reduction 2015-2030. PreventionWeb, 23.06.2015. www.preventionweb.net/files/resolutions/N1516716.pdf (Downloaded: 21.08.2015)

[6] SMEJKAL, V. - RAIS, K.: Řízení rizik. Praha, Grada, 2003.

[7] SMITH, K.: Environmental Hazards: Assessing Risk and Reducing Disaster. Sixth edition. New York, Routledge Taylor and Francis Group, 2013. DOI: https://doi. org/10.4324/9780203805305

[8] PINE, J. C.: Hazards Analysis: Reducing the Impact of Disasters. Second edition. Boca Raton, CRC Press, Taylor, 2015. DOI: https://doi.org/10.1201/b17463

[9] BIRKMANN, J. ed.: Measuring Vulnerability to Natural Hazards: Towards Disaster Resilient Societies. New York, United Nations University Press, 2013.

[10] A Global Report Reducing Disaster Risk a Challenge for Development. New York, United Nations Development Programme, 2004.

[11] CUTTER, S. L. - BORUFF, B. J. - SHIRLEY, W. L.: Social Vulnerability to Environmental Hazards. Social Science Quarterly, 842 (2003), 242-261. DOI: https://doi. org/10.1111/1540-6237.8402002

[12] United Nations: 2009 UNIDSR Terminology on Disaster Risk Reduction. UNISDR, 2009. www.unisdr.org/we/inform/publications/7817 (Downloaded: 05.09.2015)

[13] MOENCH, M. - DIXIT, A. - AHMED, S.: Working with the Winds of Change: Toward Strategies for Responding to the Risks Associated with Climate Change and other Hazards. Second edition. Kathmandu, Published by the ProVention Consortium, Institute for Social and Environmental Transition-International, and Institute for Social and Environmental Transition-Nepal, 2007.

[14] OSBORN, A. F.: Applied Imagination: Principles and Procedures of Creative ProblemSolving. New York, Ch. Scribner's Sons, 1995.

[15] PAULUS, P. B. - NIJSTAD, B. A.: Group Creativity. Innovation through Collaboration. Oxford, Oxford University Press, 2003. DOI: https://doi.org/10.1093/ acprof:oso/9780195147308.001.0001

[16] ANDĚL, J.: Základy matematické statistiky. Praha, Matfyzpress, 2005. 